\title{
$\begin{array}{ll}\text { Research Square } & \text { Preprints are preliminary reports that have not undergone peer review. } \\ \text { They should not be considered conclusive, used to inform clinical practice, }\end{array}$ or referenced by the media as validated information. \\ Information Seeking Behavior about Cancer and Associated Factors among Students at DebreTabor University, Ethiopia, 2019: Cross sectional study
}

\section{Adugna Gedefaw}

State University of New York Downstate Medical Center

Tesfahun M. Yilma

University of Gondar College of Medicine and Health Sciences

Berhanu F. Endehabtu ( $\boldsymbol{V}$ berhanufikadie@gmail.com )

University of Gondar College of Medicine and Health Sciences https://orcid.org/0000-0001-7117-6407

Research article

Keywords: Cancer, Information Seeking behavior, University Student, Ethiopia

Posted Date: March 23rd, 2020

DOI: https://doi.org/10.21203/rs.3.rs-18676/v1

License: (c) (i) This work is licensed under a Creative Commons Attribution 4.0 International License.

Read Full License 


\section{Abstract}

Introduction The prevalence of cancer has been increasing and it is among the leading cause of death in in sub-Saharan Africa over the last few years which mainly influnced by life-style. Understanding the information seeking behavior of individuals, especially Students who are more likely to seek health information than other people, can be seen as an opportunity to provide resources to improve lifestyle or prevent possible health threatening behaviors among students. The main objective of this study is to determine the health information seeking about cancer among students of Debretabor University Ethiopia.

Objective The aim of this study was to assess cancer information seeking behavior (CISB) and its associated factors among students in Debre Tabor University.

Methods Institutional based cross-sectional study design was conducted from March 01-30/2019. A total of 844 students were selected using multistage stratified sampling technique. Data entry and analyses were done using Epi info version 7.2 and SPSS version 20 respectively. Descriptive statistics and multivariate logistic regression analyses were applied to determine proportion of cancer information seeking behavior and to identify factors associated.

Result The proportion of cancer information seeking by students in the past 12 month was $30.1 \%$. Their first source of information was healthcare providers (48\%) followed by Internet (27.6\%). The majority $39.8 \%$ were looked about breast cancer. Year of study, Internet access (AOR=6.07, 95\% $\mathrm{Cl}=4.05,9.10)$, health literacy level $(A O R=1.8,95 \% \mathrm{Cl}=1.21,2.68)$, self-reported health condition $(A O R=1.85,95 \% \mathrm{Cl}=1.25$, 2.73), perceived susceptibility to cancer $(\mathrm{AOR}=2.48,95 \% \mathrm{Cl}=1.47,4.2)$ and perceived severity of cancer $(A O R=3.33,95 \% \mathrm{Cl}=1.85,6.0)$ were the factors associated with cancer information seeking behavior.

Conclusion The proportion of cancer information seeking among university students was low. Year of study, internet access, being healthy, health literacy level, level of perception to cancer exposure and perception to severity of cancer were significantly associated with cancer information seeking behavior. Increase health literacy \& awareness creation about cancer for students will help to increase cancer information seeking behavior.

\section{Introduction}

Cancer is a disease caused by an uncontrolled division of abnormal cell in the part of body, and it is one of the most important causes of morbidity and mortality both in developed \& developing world $(1,2)$. The upswing of non-communicable diseases (NCD) has become an important issue for health-care systems. In the past decades, national and international public health agencies across the glove have focused to control infectious and tropical diseases in developing countries.

Projection in 2016 by WHO revealed that, the cancer burden will increase to 24 million new cases and 14.6 million cancer deaths will occur worldwide in 2035. Of this around 70 percent of cancer incidence 
will occur in developing countries (3). Ethiopia is among the developing countries that has high burden of cancer morbidity \& mortality. Findings from 2018 showed that cancer incidence rates was 206 per 100,000 in Ethiopia (4).

Efforts have been undertaken to minimize the burden of cancer in both developed and developing countries. Several African governments have developed and implemented operational national cancer control plans (5). More than 700 cancer registries were established worldwide (6). Ethiopia also has been designed different cancer prevention strategies such as; cancer comprehensive treatment and care, health promotion and disease prevention targeting on behavioral risk factors(avoid tobacco, alcohol, unhealthy diet and physical inactivity) (7).

Effective communication on cancer-related information plays a significant role in the reduction of cancer burden since, it has substantial influence on lifestyle (8). Health Information Seeking Behavior (HISB) is the ways by which people obtain information about health, disease, health risk, and health promotion (9). Effective practice of HISB could bring health-enhancing actions and serves as an important means for understanding how an individual finds health information (10). Health information seeking practice is important in stress reduction, to increases awareness towards health risk factors and cancer disease process. Currently there are plenty of information related to cancer such as cancer prevention, cancer diagnosis, treatment and recovery (11). Health Seeking information about cancer may carry out particular importance for cancer disease reduction $(8,12)$. Understanding the information seeking behavior of individuals, especially Students who are more likely to seek health information than other people, can be seen as an opportunity to provide resources to improve lifestyle or prevent possible health threatening behaviors among students. Therefore, the aim of this study was to determine the health information seeking about cancer and its associated factors.

\section{Methods And Materials}

\section{Study design and period}

An institution-based cross-sectional study design was conducted from March 01-30/2019. The quantitative method was used to describe socio-demographic characteristics of respondents, the extent of cancer information seeking and factors associated with cancer information seeking among students.

\section{Study area and setting}

Debre Tabor University is one of the newly established public higher education institutions in Ethiopia. The university has a clinic located centrally on the campus and it gives primary healthcare services. The clinic has laboratory, consultation, pharmacy, nursing services, medical records, wound dressing units and in-patient bed facilities for short term admissions. The University has a total of 9572 students.

\section{Sample size determinations}


The sample size was calculated using single population proportion formula with the following assumptions: $95 \%$ confidence level $(\mathrm{Cl}), \mathrm{Z}(1-\mathrm{a} / 2)=1.96)$, an expected proportion of cancer information seeking behavior of $50 \%$, and $5 \%$ margin of error. As to investigator knowledge, in the country, there were no previously conducted studies which determined the proportion of cancer information seeking behavior in higher institution. Hence, $50 \%$ was taken to estimate the required sample size. Furthermore, two sampling stage was applied to reach to the final study units in the process. Considering design effect of two and $10 \%$ non-response the final sample size was 844 .

\section{Sampling methods and procedure}

A stratified multi-stage sampling method was employed to select study subjects. In the first stage, departments were stratified based on health-related and not-health related. And then, proportional allocation was employed to select $13(30 \%)$ departments, 2 from health and 11 from non-health related departments by using simple random sampling, we assumed that there was a difference between departments for cancer information seeking. Next departments were stratified by their years of study; we assumed that their years of study and duration of stay in the campus would affect cancer information seeking behavior among students. The total number of students in selected departments was distributed proportionally based on the total number of students in each year of study. In the second stage, individual students from each stratum were selected by using simple random sampling technique.

\section{Study variables}

Dependent variable: Cancer information seeking Yes/ No and was coded as 1 and 0 respectively.

\section{Independent variables}

Socio-Demographic Factors: age, gender, year of study, filed of study, club participation, religion, ethnicity, prior residence, internet access.

Behavioral Factors: Smoking, Alcohol drinking, Risky sexual behavior, physical activity.

Health status: General health status, Self-cancer disease history, family cancer disease history.

Health literacy level: Perceived susceptibility to cancer, Perceived severity of cancer, Perceived health selfefficacy.

\section{Operational definition}

Cancer information seeking: "Yes" was defined as those who had looked for cancer information within the last year from any source (13).

\section{Measurements:}


Cancer information seeking: Respondents were asked two questions about their information seeking "Have you looked for information intentionally about cancer from any source?" and "about how long ago was that?"(14).

Smokers: defined as a respondent who smoke currently either every day or sometimes.

Alcohol drinking: drinker or alcohol miss use defined as if the AUDIT-C mean score is $\geq 4$ for male and $\geq$ 3 for females (15).

Measurements: The AUDIT-C (Alcohol Use Disorder Identification Test) is quantifies alcohol misuse based on three Likert scale questions is a modified, shortened version of the 10-question AUDIT instrument developed by WHO (15).

Health self-efficacy: Respondents were asked questions about their level of confidence ranges from completely confident (5) to not at all confident (1), overall, how confident are you about your ability to take good care of your health?

Perceived susceptibility: Respondents were asked questions about their perception on level of susceptibility for cancer ranging from very likely (5) to very unlikely (1). How concerned are you about getting cancer disease?

Perceived severity: Respondents were asked questions about their own perception on cancer severity. Decide When I think about cancer, I automatically think about death" ranging from not at all (1) to extremely (5).

Health literacy: European health literacy survey questionnaire was used to measure health literacy and HLS-EU-Q with 47 items. The 47 items is assessed using a 4-point scale (very easy=4, easy $=3$, difficult=2 and very difficult $=1$ ) and the score is divided into 4 categories: 'inadequate', 'problematic', 'sufficient' and 'excellent' health literacy. Index is computed by the formula, Index=mean- $1 *(50 / 3)$. From the formula, if the index is In between 1 and 13.75 the health literacy is "Inadequate", In between 13.76 and 25.5 the health literacy is "Problematic", In between 25.6 and 37.5 the health literacy is "Sufficient" and $>37.5$ the health literacy is "Excellent" (16).

\section{Data collection tools}

Self-administered Amharic version questionnaire comprised of demographic, behavioral, health literacy, health status, psychological factors and looks for cancer information was used. The Health literacy questioner is adopted from European Health literacy survey (16). Cancer information seeking questioners are mainly adapted from the Health Information National Trend survey 2014 (17).

\section{Data collection procedures}

For quantitative study, five data collectors and two supervisors were recruited. The questionnaire was first developed in English and then translated to Amharic language and again back to English for 
appropriateness and easiness in approaching the study participants. The questionnaire was pre-tested for suitability prior to the actual data collection in the University of Gondar.

\section{Data quality control}

Data was collected by well-trained data collectors using pretested questionnaires. Training was given for two days to supervisors and data collectors on the objective of study. Close follow up and supervision during data collection time was carried out. Data were reviewed and checked for its completeness before entered and analyses.

\section{Data processing \& analysis}

Data were entered into Epi- info version 7.2 and exported into SPSS version 20.0 for further statistical analysis. The data were cleaned, coded, and analysed. Descriptive analysis was done to describe sociodemographic characteristics of the study participants and the outcome variable. Binary logistic regression analysis was done to identify association between independent and cancer information seeking behavior at $\mathrm{p}$-value less than 0.2 . To identify factors significantly associated with the outcome variables (cancer information seeking yes/no), adjusted odds ratio (AOR) with 95\% confidence interval (Cl) was used. Variable having p-value less than 0.05 were considered as significant predictors. Hosmer and Lemeshow goodness of fit test was checked that was 0.17 p-values.

\section{Ethical consideration}

Ethical approval was obtained from University of Gondar, Institute of public health ethical review committee. Written permission letter was secured from Debre Tabor University. From each participant written informed consent was obtained. Their name was omitted for assurance of confidentiality and privacy. Interview was performed at suitable and secure place to respondents. Finally, questionnaire was cleaned, stored and analysed at secured place.

\section{Results}

A total of 844 students were participated in this study with 100\% response rate. The mean age of the participants was $23.59 \pm 3.78$ SD year which ranges from18 to 38 years. Majority $80.5 \%(679 / 844)$ of the study participants had no voluntary health club participation, 53.9\% (455/844) were previously resided in rural area, 67.5\% (570/844) were orthodox Christian and the majority $90.3 \%(762 / 844)$ were from nonhealth department (Table 1).

Table 1: Socio-demographic characteristics of respondents at Debre Tabor University, northern Ethiopia 2019 (n=844) 


\begin{tabular}{|c|c|c|c|}
\hline Variables & Category & Frequency & Percent \\
\hline \multirow[t]{2}{*}{ Age ( in years) } & $\leq 23$ & 391 & 46.3 \\
\hline & $>24$ & 453 & 53.7 \\
\hline \multirow[t]{2}{*}{ Gender } & Male & 442 & 52.4 \\
\hline & Female & 402 & 47.6 \\
\hline \multirow[t]{2}{*}{ Prior residence } & Urban & 389 & 46.1 \\
\hline & Rural & 455 & 53.9 \\
\hline \multirow[t]{2}{*}{ Club participation } & Yes & 165 & 19.5 \\
\hline & No & 679 & 80.5 \\
\hline \multirow[t]{4}{*}{ Religion } & Orthodox & 570 & 67.5 \\
\hline & Muslim & 151 & 17.9 \\
\hline & Protestant & 86 & 10.2 \\
\hline & Catholic & 37 & 4.3 \\
\hline \multirow[t]{2}{*}{ Field of study } & Health-related & 82 & 9.7 \\
\hline & Not-Health-related & 762 & 90.3 \\
\hline \multirow[t]{4}{*}{ Year of study } & $1^{\text {st }}$ year & 361 & 42.8 \\
\hline & $2^{\text {nd }}$ year & 234 & 27.7 \\
\hline & $3^{\text {rd }}$ Year & 194 & 23.0 \\
\hline & $4^{\text {th }}$ Year & 55 & 6.5 \\
\hline \multirow[t]{3}{*}{ Marital status } & Single & 718 & 85.1 \\
\hline & Married & 120 & 14.2 \\
\hline & *Others & 6 & 0.7 \\
\hline
\end{tabular}

*Others $=$ widowed, Divorce

\section{Behavioral, personal and family history to cancer}

About $11.1 \%$ (94/844) of study participant's drunk alcohol and 3.4\% (29/844) had history of cigarette smoking. Among the study participants eight students $0.9 \%(8 / 844)$ had personal history of cancer and only $0.7 \%(6 / 844)$ had family history of cancer (Table 2$)$.

Table 2: Behavior, personal and family history of students to cancer in Debre Tabor University 2019

\begin{tabular}{llll}
\hline \multirow{2}{*}{ Alcohol drinking } & Categories & Frequency & Percent (\%) \\
\hline \multirow{2}{*}{ Physical activity } & Yes & 94 & 11.1 \\
\cline { 2 - 4 } & No & 750 & 88.9 \\
\hline \multirow{2}{*}{ Smoking } & Active & 411 & 48.7 \\
\cline { 2 - 4 } & Inactive & 433 & 51.3 \\
\hline \multirow{2}{*}{ Risky sexual behavior } & Smoker & 29 & 3.4 \\
\cline { 2 - 4 } & Non-smoker & 815 & 96.6 \\
\hline \multirow{2}{*}{ General health condition } & Yes & 17 & 2 \\
\cline { 2 - 4 } & Feel healthier & 429 & 98.8 \\
\cline { 2 - 4 } & Less healthier & 415 & 49.2 \\
\hline Self-cancer history & Yes & 8 & 0.9 \\
\cline { 2 - 4 } & No & 836 & 99.1 \\
\hline Family cancer history & Yes & 606 & 71.8 \\
\cline { 2 - 4 } & No & 232 & 27.5 \\
\cline { 2 - 4 } & Not sure & & 98.7 \\
\hline
\end{tabular}




\section{Psychological and health literacy for cancer information seeking behavior}

Among the study participants only 37.2\% (314/844) had adequate health literacy level. Majority $82.9 \%$ (700/844) of study participants perceived that cancer is sever disease and $21(177 / 844)$ of students perceived that they were very concerned about cancer (Table 3).

Table 3: Psychological and health literacy variable to cancer information seeking behavior among student in Debre Tabor University 2019

\begin{tabular}{llll}
\hline & Categories & Frequency & Percent (\%) \\
\hline Health literacy & Adequate & 314 & 37.2 \\
& Limited & 530 & 62.8 \\
\hline \multirow{2}{*}{ Health self-efficacy } & Confident & 437 & 51.8 \\
& Not confident & 407 & 48.2 \\
\hline \multirow{2}{*}{ Perceived susceptibility to cancer } & Very concerned & 177 & 21.0 \\
& Concerned & 435 & 51.5 \\
\hline Perceived severity of cancer & Not concerned & 232 & 27.5 \\
& Sever & 700 & 82.9 \\
& Not sever & 144 & 17.1 \\
\hline
\end{tabular}

\section{Cancer health information seeking behavior}

Among the study participants $30.1 \%$ (254/844) (95\% Cl: (26.9\%-33.3\%) were searched information about cancer at least one time in the past 12 months. About $54.9 \%(45 / 82)$ of study participants from health departments seek their were seek health information about cancer and only $27.4 \%(209 / 553)$ of study participants from non-health departments seek health information about cancer(Figure 1).

\section{Source of information for cancer}

Out of 254 cancer information seeker, 48\% (122/254) of participants' first source of information was healthcare providers followed by Internet $27.6 \%$ (70/254). Also, they sought health information about cancer from families, friends and Medias (Figure2).

\section{Type and frequency of cancer information}

From the participants $37 \%(94 / 254)$ were looking information about cancer prevention strategies, $36.2 \%$ (92/254) were looking information about sign and symptoms of cancer, $19.3 \%(49 / 254)$ seek information about cancer treatment and 7.48\% (19/254) information about cancer diagnosis. With regard to the types of cancer site-specific information about $39.8 \%$ (165/432) of participants were looking about breast cancer followed by cervical cancer $22 \%$ (93/432). Liver cancer and colon cancer were the list cancer sitespecific information sought by the study participants (figure3).

More than half of the participants $53.5 \%$ (136/254) were seeking information occasionally while; nearly one-fourth of the participants $28.7 \%$ (73/254) were seeking information about cancer at least once a month(figure4) 


\section{Factors associated with cancer information seeking}

Participants' field of study, year of study, club participation, Internet access, Physical activity, health status and health literacy, perceived severity to cancer, perceived susceptibility and self-efficacy were significant in bi variable logistic regression. Among the variables which were significant in bi variable logistic regression; year of study, Internet access, Physical activity, health status, health literacy, perceived severity and perceived susceptibility were identified as factors associated with cancer information seeking behavior through multi-variable logistic regression.

The result of this study revealed that the odds of seeking information about cancer among participants whose year of study was third and fourth years were two (AOR=2.29, $95 \% \mathrm{Cl}=1.43,3.69)$ and four times $(A O R=3.92,95 \% \mathrm{Cl}=1.82,8.45)$ higher as compared with first year students. The odds of seeking information about cancer among participants who were currently physically active was three times (AOR=3.05, 95\% Cl=2.10, 4.43) higher to seek cancer information when compared to physically inactive. The odds of seeking information about cancer among participants who had Internet access was six times $(A O R=6.07,95 \% \mathrm{Cl}=4.05,9.10)$ higher when compared to those who had no internet access.

Information seeking about cancer by participants who had adequate health literacy level was two times $(A O R=1.8,95 \% \mathrm{Cl}=1.21,2.68)$ higher than those who had low health literacy level. The odds of seeking information about cancer among participants who had feel better about their health was two times $(A O R=1.85,95 \% \mathrm{Cl}=1.25,2.73)$ higher when compared to those who had feel less healthy.

Table 6: Bi-variable and multivariable analysis of factors for cancer information seeking behavior among students in Debre Tabor University, Ethiopia $2019(\mathrm{n}=844)$

* indicates $0.05<\mathrm{p}>0.001, * *$ indicates $\mathrm{p}<0.001,1=$ reference category

\section{Discussion}

In low income settings, peoples are at risk of three burdens health problems such as; communicable disease, traffic accident and non-communicable disease. With all this cancer is among the public health importance and with low awareness by the community. University students are at risk for many health problems due to lack of awareness and high exposure for risk factors. Also, cancer is very devastating disease and the capacity of the country to screen, diagnose and treat cancer is very limited. In this study, students' health seeking behavior about cancer and its associated factor was assessed at Debretabor University. The overall health information seeking behavoiur of students for cancer was $30.1 \%$ (95\% $\mathrm{Cl}=26.9,33.3)$. This finding is higher than study conducted in Malaysia which showed the prevalence of health information seeking behavoiur of breast cancer was $22.5 \%$ (18). This diffrence could be due to the former study includes only breast cancer. Also, the finding from the current is higher than a study conducted in Hadiya zone southern Ethiopia which showed the prevalence of health information seeking behavoiur about cervical cancer was $14.2 \%$ (19). This diffrence could be due to socio-demographic difference. The former study included community child bearing women. University students had better health literacy status which in turn increases their access to information about cancer. On the other hand, 


\begin{tabular}{|c|c|c|c|c|}
\hline \multirow[t]{2}{*}{ Variables } & \multicolumn{2}{|c|}{ Cancer information seeking } & \multirow[t]{2}{*}{ COR (95\%) } & \multirow[t]{2}{*}{ AOR (95\%) } \\
\hline & Yes (\%) & No (\%) & & \\
\hline \multicolumn{5}{|l|}{ Club participation } \\
\hline Yes & $69(8.2)$ & $96(11.4)$ & $1.92(1.35,2.73)$ & $1.49(0.96,2.30)$ \\
\hline No & $185(21.9)$ & $494(58.5)$ & 1 & 1 \\
\hline \multicolumn{5}{|l|}{ Field of study } \\
\hline Health & $45(5.3)$ & $37(4.4)$ & $3.22(2.03,5.11)$ & $1.42(0.78,2.56)$ \\
\hline Non health & $209(24.8)$ & $553(65.5)$ & 1 & 1 \\
\hline \multicolumn{5}{|l|}{ Year of study } \\
\hline First year & $76(9)$ & 285 (33.8) & 1 & 1 \\
\hline Second year & 75 (8.9) & 159 (18.8) & $1.77(1.22,2.57)$ & $1.32(0.84 .2 .05)$ \\
\hline Third year & $77(9.1)$ & 117 (13.9) & $2.46(1.68,3.62)$ & $2.29(1.43,3.69)^{*}$ \\
\hline Fourth year & $26(3.1)$ & $29(3.4)$ & $3.36(1.87,6.04)$ & $3.92(1.82,8.45) *$ \\
\hline \multicolumn{5}{|l|}{ Internet access } \\
\hline Yes & $210(24.9)$ & $262(31)$ & $5.975(4.16,8.59)$ & $6.07(4.05,9.10) * *$ \\
\hline No & $44(5.2)$ & $328(38.9)$ & 1 & 1 \\
\hline \multicolumn{5}{|l|}{ Physical activity } \\
\hline Active & $180(21.3)$ & $231(27.4)$ & $3.78(2.75,5.20)$ & $3.05(2.10,4.43) * *$ \\
\hline Inactive & $74(8.8)$ & $359(42.5$ & 1 & 1 \\
\hline \multicolumn{5}{|l|}{ Health literacy } \\
\hline Limited & 109 (12.9) & 421 (49.9) & 1 & 1 \\
\hline Adequate & $145(17.2)$ & $169(20)$ & $3.31(2.44,4.50)$ & $1.80(1.21,2.68) *$ \\
\hline \multicolumn{5}{|l|}{ Health status } \\
\hline Less healthier & $95(11.3)$ & 334 (39.6) & 1 & 1 \\
\hline Feel healthier & $159(18.8)$ & $256(30.3)$ & $2.18(1.66,2.95)$ & $1.85(1.25,2.73) *$ \\
\hline \multicolumn{5}{|c|}{ Perceived susceptibility } \\
\hline Not concerned & $55 \quad(6.5)$ & $177(21.0)$ & 1 & 1 \\
\hline Concerned & $116(13.7)$ & 319 (37.8) & $1.17(0.81,1.69)$ & $1.52(0.96,2.41)$ \\
\hline Very concerned & $83 \quad(9.8)$ & $94(11.1)$ & $2.84(1.86,4.34)$ & $2.48(1.47,4.20) *$ \\
\hline \multicolumn{5}{|l|}{ Perceived severity } \\
\hline Not sever & $20 \quad(2.4)$ & $124(14.7)$ & 1 & \\
\hline Sever & $234(27.7)$ & $466(55.2)$ & $3.11(1.89,5.12)$ & $3.33(1.85,6.00) * *$ \\
\hline \multicolumn{5}{|l|}{ Health self-efficacy } \\
\hline Not confident & $86(10.2)$ & $321(38.0)$ & 1 & \\
\hline Confident & $168(19.9)$ & $269(31.9)$ & $2.33(1.71-316)$ & $1.39(0.92,2.12)$ \\
\hline
\end{tabular}

health information seeking behavior of students in this study was lower as compared to different studies conducted among cancer survivor in USA(53\%, 68\%, 47.4\%) $(13,20,21)$.This might be due to high perception to the cancer severity since they are cancer survivor patients and they have high level of health literacy and awareness about cancer information source. Similarly A study conducted in Malaysia among students on health information seeking behavoiur was 80\% (22). This difference could be the previous study was done on general health information seeking behavior.

Regarding the source of cancer information, about $48 \%$ of cancer information seekers prefer health care provider as the primary source followed by the Internet as secondary source of cancer information (27.6\%). This study is consistent with a study conducted at different regions in Ethiopia (23) .This might be health care providers are the most trusted source of health information and cancer-related information provided from health care providers is easily understandable since students encounter a problem in understanding jargon words independently.

Respondents Year of study was significantly associated with cancer information seeking behavior. Senior students were more seeker of health information about cancer than juniors. This finding is in line with a study conducted in China/Hong Kong. Participants with low educational attainment were less likely seek health information(24). The probable explanation for this could be when the student's year of study 
increases their awareness towards the impact of cancer disease on human health increases and this leads to seek health information about cancer.

In this study, students' health information seeking behavior about cancer was associated with physical activities. Students who had physical activity were three times more likely search information about cancer compared to those students who were physically inactive. This study appeared to be consistent with study done in Egypt (25). The possible explanation may be: those students who are already involved in daily exercise have better understanding towards promoting their health and they are concerned about their health status which in turn leads to seeking information about cancer.

In this study, perceived susceptibility to cancer and cancer information seeking behavior was significantly associated. Participants who are Very concerned about getting cancer disease were two times more likely seek information about cancer than participants who are not concerned at all about getting cancer disease. This study is consistent with a study conducted in Belgium (26). Participants who perceive susceptible for cancer are likely to seek health information to reduce their exposure to cancer.

Similarly Perceived severity of cancer also associated with cancer information seeking behavior. Participants whose perceptions about cancer as sever sought health information about cancer were three times higher as compared with those who had no perception about severity of cancer. This study is supported by a study conducted in USA 2013 (21). Cancer severity can be described as deterministic thoughts about the external causes of the disease and the inevitability of death at diagnosis. Individual who perceives cancer as sever want to know the risk factors, prevention methods, diagnosis and treatment of cancer. In addition internet access is associated with cancer information seeking. Health information seeking behavior by participants who had Internet access was six times higher as compared with those who had no internet access. This is due to the reasons of availability and ease of accessing information, privacy and confidentiality (27).

Participants' health literacy status also significantly associated with cancer information seeking behavior. Health information seeking behavior about cancer by participants who had adequate health literacy was two times more likely sought information for cancer than who had limited health literacy. This study is consistent with other study conducted in America (21). The probable explanation for this association might be, whenever individuals health literacy increase they will be concerned about their health since cancer is the most devastating health problem. Accordingly, they will retrieve information about cancer due to the reason they fear to develop the health problem $(21,28)$. Club participation, field of study and health self-efficacy was not significantly associated with health information seeking behavior about cancer.

Our study gives evidence on health information seeking behavior of university students about cancer. There are some limitations that should be noted. First, the study was facility based cross sectional study which couldn't tell as the causal inference. Self-reported data collection was used and there may have been recall bias by the respondents. 


\section{Conclusion}

Generally, the proportion of information seeking behavior about cancer among university students was low. The finding also confirms health care provider had been used as a primary source of information about cancer followed by internet. Most of the participants were retrieved information mainly for the purpose keeping protected themselves and their family or friends. In this study participants were concerned to retrieve information regarding cancer was primarily about breast cancer even though there is different site-specific cancer disease. Most of participants were concerned to retrieve information with Regards about the sign symptom and prevention methods of cancer. Year of study, internet access, physical activity, health status, health literacy, perceived susceptibility, and perceived severity were factors significantly associated with information seeking behavior about cancer. Increasing health literacy status and availing internet access will increase the health information seeking behavior of students about cancer.

\section{Abbreviations}

CISB: Cancer Information Seeking Behavior, HISB: Health Information Seeking Bhavior, NCD: NonCommunicable Diseases, WHO: World Health Organization

CISB: Cancer Information Seeking Behavior, HISB: Health Information Seeking Bhavior, NCD: NonCommunicable Diseases, WHO: World Health Organization

\section{Declarations}

\section{Ethics approval and consent to participate}

The study protocol was reviewed and approved by ethical review board of University of Gondar and written consent was obtained from each study participant.Permission letter also obtained from Debretabor Hospital. Names of patients and other personal identifiers were not included in the data collection tool.

\section{Consent for publication}

Not applicable.

\section{Availability of data and materials}

The datasets generated and/or analysed during the current study will be available upon request from the corresponding author.

\section{Competing interests}

The authors declare that they have no competing interests. 


\section{Funding}

No funding.

\section{Authors' contributions}

All authors made substantial contributions to conception and design, acquisition of data, or analysis and interpretation of data; took part in drafting the article or revising it critically for important intellectual content; gave final approval of the version to be published; and agree to be accountable for all aspects of the work.

\section{Acknowledgements}

The authors would like to thank University of Gondar institute of public health for the approval of ethical clearance and Debretabor University and data collectors, supervisors and study participants.

\section{References}

1. Boland CR, Thibodeau SN, Hamilton SR, Sidransky D, Eshleman JR, Burt RW, et al. A National Cancer Institute Workshop on Microsatellite Instability for cancer detection and familial predisposition: development of international criteria for the determination of microsatellite instability in colorectal cancer. AACR; 1998.

2. Zech DF, Grond S, Lynch J, Hertel D, Lehmann KA. Validation of World Health Organization Guidelines for cancer pain relief: a 10-year prospective study. Pain. 1995;63(1):65-76.

3. Ferlay J, Soerjomataram I, Dikshit R, Eser S, Mathers C, Rebelo M, et al. Cancer incidence and mortality worldwide: sources, methods and major patterns in GLOBOCAN 2012. International journal of cancer. 2015;136(5):E359-E86.

4. Timotewos G, Solomon A, Mathewos A, Addissie A, Bogale S, Wondemagegnehu T, et al. First data from a population based cancer registry in Ethiopia. Cancer epidemiology. 2018;53:93-8.

5. Stefan DC, Elzawawy AM, Khaled HM, Ntaganda F, Asiimwe A, Addai BW, et al. Developing cancer control plans in Africa: examples from five countries. The lancet oncology. 2013;14(4):e189-e95.

6. Bray F, Soerjomataram I, Mery L, Ferlay J. Improving the quality and coverage of cancer registries globally. The Lancet. 2015;386(9998):1035-6.

7. NON-COMMUNICABLE O. NATIONAL STRATEGIC ACTION PLAN (NSAP) FOR PREVENTION \& CONTROL OF NON-COMMUNICABLE DISEASES IN ETHIOPIA.

8. Kelly B, Hornik R, Romantan A, Schwartz JS, Armstrong K, DeMichele A, et al. Cancer information scanning and seeking in the general population. Journal of health communication. 2010;15(7):73453.

9. Lambert SD, Loiselle CG. Health information-seeking behavior. Qualitative health research. 2007;17(8):1006-19. 
10. CHAUDHURI MS, LE MT, WHITE MC, Thompson H, Demiris G. Examining health information-seeking behaviors of older adults. Computers, informatics, nursing: CIN. 2013;31(11):547.

11. Viswanath $\mathrm{K}$. The communications revolution and cancer control. Nature reviews cancer. 2004;5(10):828.

12. Niederdeppe J, Frosch DL, Hornik RC. Cancer news coverage and information seeking. Journal of health communication. 2008;13(2):181-99.

13. Shim M, Kelly B, Hornik R. Cancer information scanning and seeking behavior is associated with knowledge, lifestyle choices, and screening. Journal of Health Communication. 2006;11(S1):157-72.

14. Services USDoHaH. National Institutes of Health U.S. Department of Health and Human services. 2014.

15. Bush K, Kivlahan DR, McDonell MB, Fihn SD, Bradley KA. The AUDIT alcohol consumption questions (AUDIT-C): an effective brief screening test for problem drinking. Archives of internal medicine. 1998;158(16):1789-95.

16. Sørensen K, Van den Broucke S, Pelikan JM, Fullam J, Doyle G, Slonska Z, et al. Measuring health literacy in populations: illuminating the design and development process of the European Health Literacy Survey Questionnaire (HLS-EU-Q). BMC public health. 2013;13(1):948.

17. Finney Rutten LJ, Davis T, Beckjord EB, Blake K, Moser RP, Hesse BW. Picking up the pace: changes in method and frame for the health information national trends survey (2011-2014). Journal of health communication. 2012;17(8):979-89.

18. Muhamad M, Afshari M, Mohamed NA. Internet Use and Breast Cancer Survivors. Turkish Online Journal of Educational Technology-TOJET. 2011;10(4):241-7.

19. Habtu Y, Yohannes S, Laelago T. Health seeking behavior and its determinants for cervical cancer among women of childbearing age in Hossana Town, Hadiya zone, Southern Ethiopia: community based cross sectional study. BMC cancer. 2018;18(1):298.

20. Claridy MD, Hudson MM, Caplan L, Mitby PA, Leisenring W, Smith SA, et al. Patterns of Internet-based health information seeking in adult survivors of childhood cancer. Pediatric blood \& cancer. 2018;65(5):e26954.

21. Kobayashi LC, Smith SG. Cancer fatalism, literacy, and cancer information seeking in the American public. Health Education \& Behavior. 2016;43(4):461-70.

22. Yilma TM, Inthiran A, Reidpath D, Orimaye SO. Health Information Seeking and its Associated Factors among University Students: A Case in a Middle-Income Setting. Health. 2017.

23. Shiferaw N, Brooks MI, Salvador-Davila G, Lonsako S, Kassahun K, Ansel J, et al. Knowledge and awareness of cervical cancer among hiv-infected women in ethiopia. Obstetrics and gynecology international. 2016;2016.

24. Wang MP, Viswanath K, Lam TH, Wang X, Chan SS. Social determinants of health information seeking among Chinese adults in Hong Kong. PloS one. 2013;8(8):e73049. 
25. Ghweeba M, Lindenmeyer A, Shishi S, Abbas M, Waheed A, Amer S. What predicts online health information-seeking behavior among egyptian adults? a cross-sectional study. Journal of medical Internet research. 2017;19(6):e216.

26. Nelissen S, Beullens K, Lemal M, Van den Bulck J. Fear of cancer is associated with cancer information seeking, scanning and avoiding: a cross-sectional study among cancer diagnosed and non-diagnosed individuals. Health information and libraries journal. 2015;32(2):107-19.

27. Ibegbulam IJ, Akpom CC, Enem FN, Onyam DI. Use of the Internet as a source for reproductive health information seeking among adolescent girls in secondary schools in Enugu, Nigeria. Health Information \& Libraries Journal. 2018;35(4):298-308.

28. Sparks L, Nussbaum JF. Health literacy and cancer communication with older adults. Patient education and counseling. 2008;71(3):345-50.

\section{Note Regarding Tables}

Tables 4 and 5 were omitted by the authors in this version of the paper.

\section{Figures}

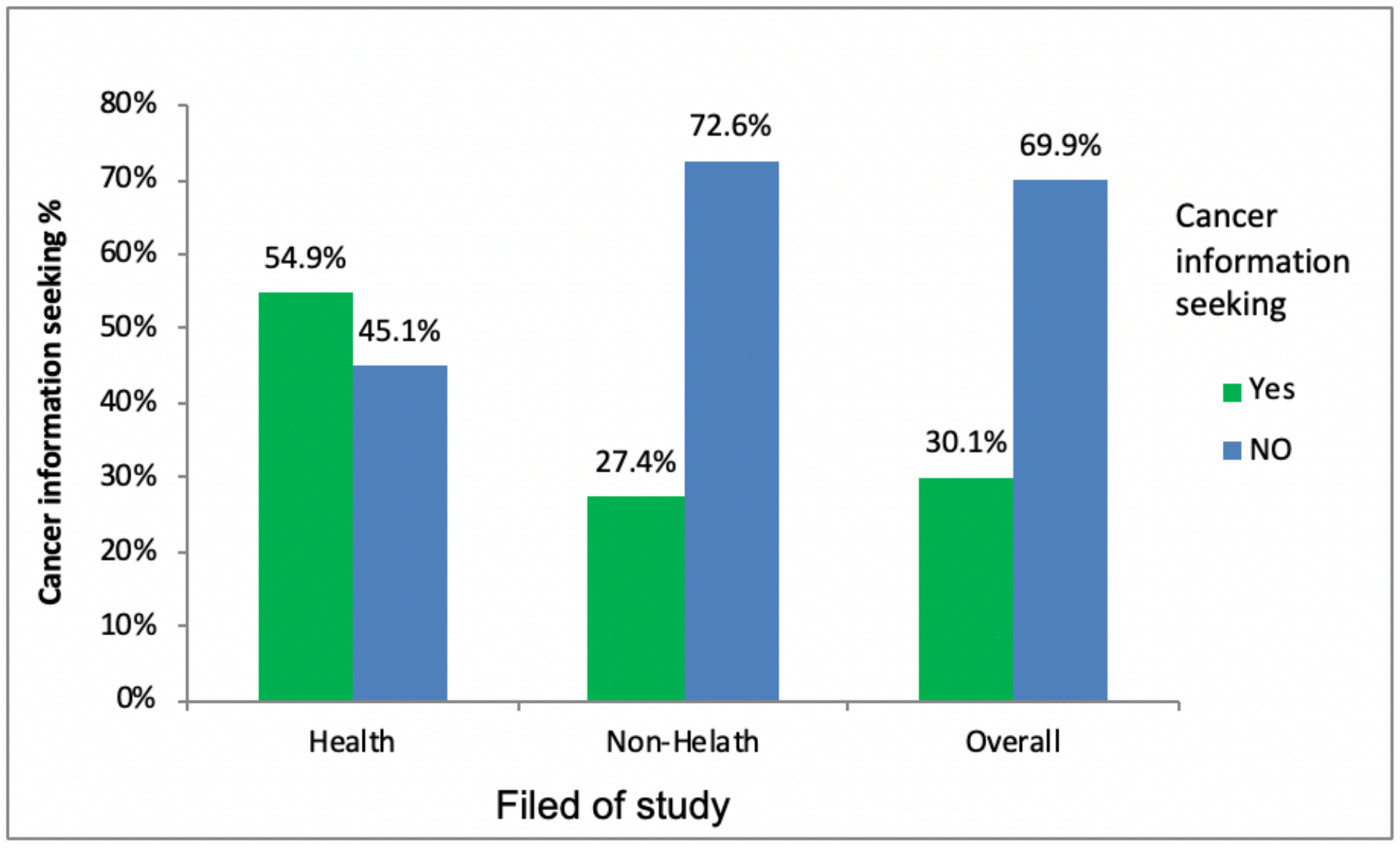

Figure 2 
Cancer information seeking behavior by field of study in Debre Tabor University 2019.

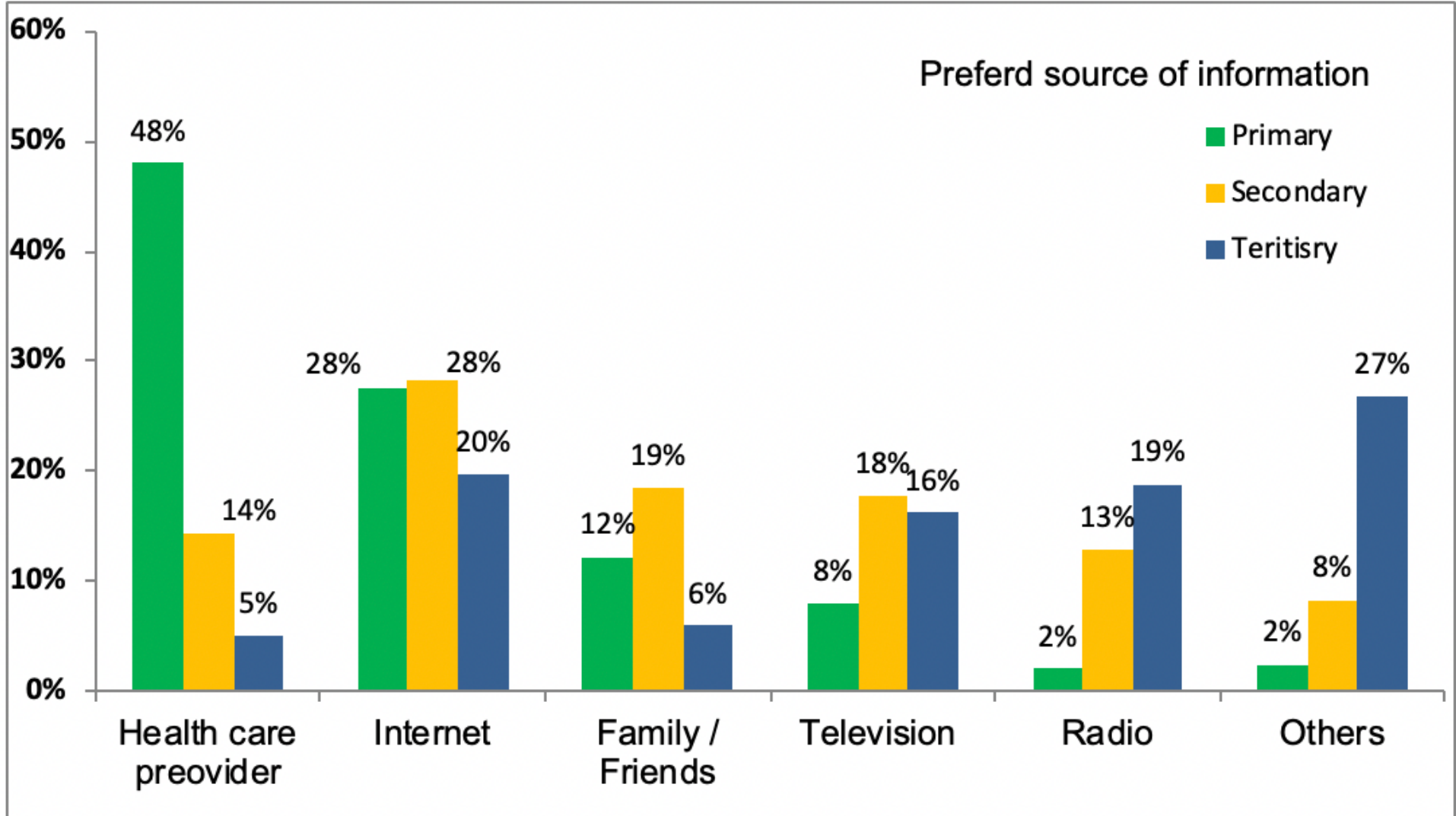

Figure 4

Preferred source of information for cancer among participants in Debre Tabor University, 2019 ( $n=254)$

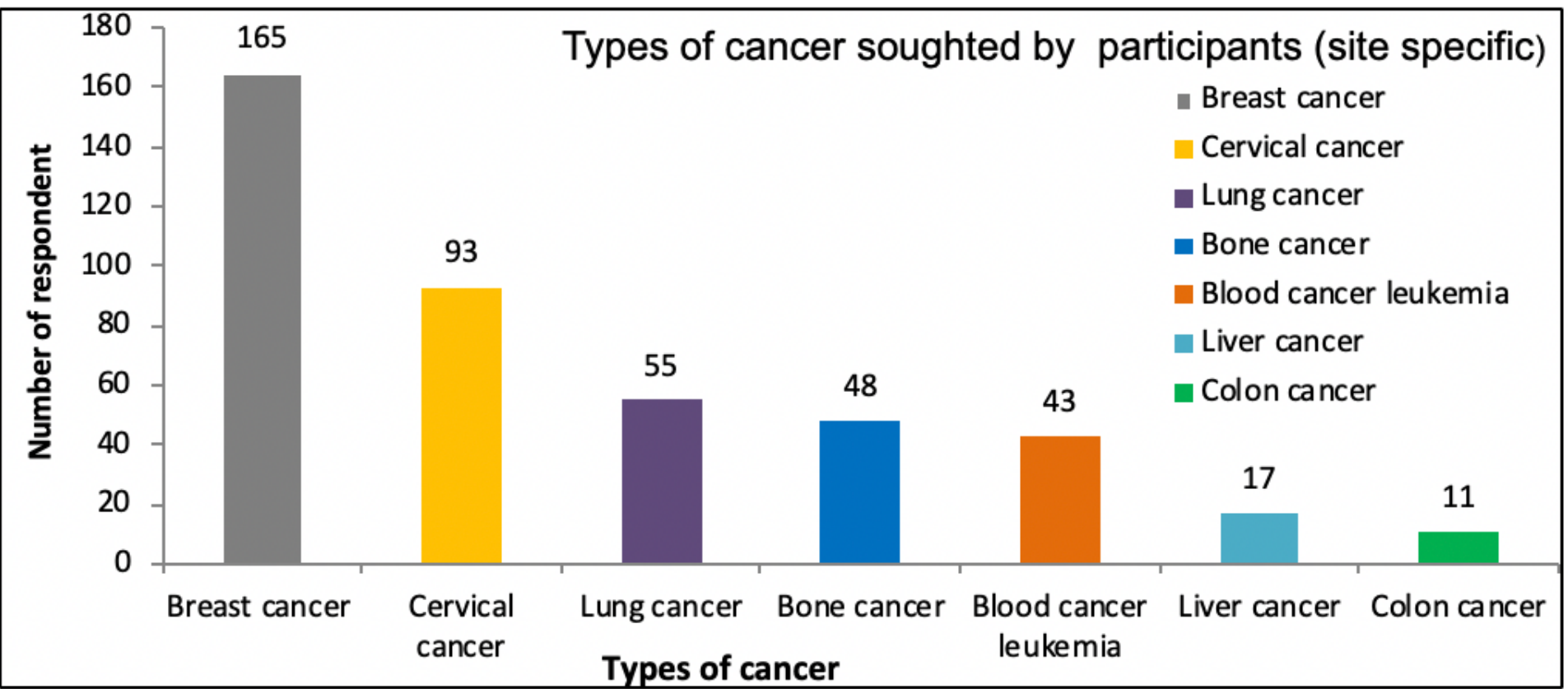

Figure 6

Types of cancer site-specific information sought by respondent in Debre Tabor University $(n=254)$. 


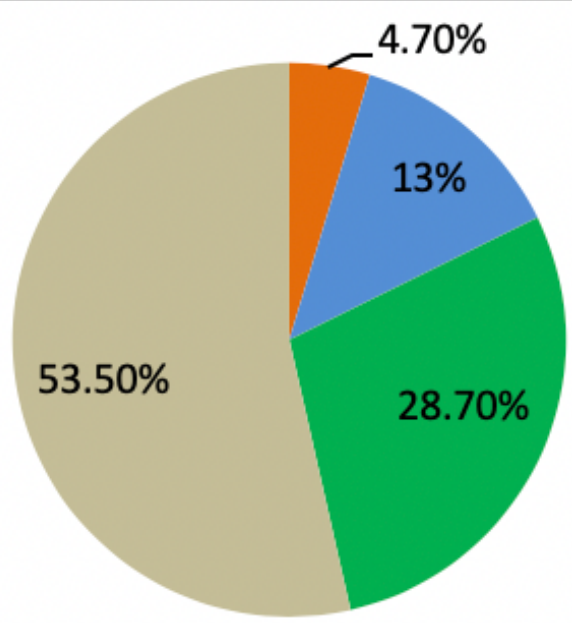

Frequncey of information seeking Every day

Once a week

Once a month

Occationally

Figure 8

Frequency of information seeking behavior about cancer in Debre Tabor University $2019 n=(254)$ 